\title{
Long-term hemorrhagic risk in pediatric patients with arteriovenous malformations
}

\author{
Wuyang Yang, MD, Heather Anderson-Keightly, Erick M. Westbroek, MD, Justin M. Caplan, MD, \\ Xiaoming Rong, MD, Alice L. Hung, BA, Geoffrey P. Colby, MD, PhD, Alexander L. Coon, MD, \\ Rafael J. Tamargo, MD, Judy Huang, MD, and Edward S. Ahn, MD
}

Department of Neurosurgery, Johns Hopkins University School of Medicine, Baltimore, Maryland

\begin{abstract}
OBJECTIVE Compared with the general population, the specific natural history of arteriovenous malformations (AVMs) in pediatric patients is less well understood. Furthermore, few pediatric studies have compared posttreatment hemorrhagic risk and functional outcome across different treatment modalities. The objective of this study was to elucidate these points.

METHODS The authors retrospectively reviewed all pediatric patients with AVMs evaluated at their institution between 1990 and 2013. The AVM natural history was represented by hemorrhagic risk during the observation period. For treated patients, the observation period was defined as the interval between diagnosis and treatment. Posttreatment hemorrhagic risk and functional outcomes were also assessed.

RESULTS A total of 124 pediatric patients with AVMs were evaluated, and 90 patients $(72.6 \%)$ were retained through follow-up. The average patient age was $13.3 \pm 3.8$ years, with a mean follow-up period of 9.95 years. The overall AVM obliteration rate was $59.7 \%$. Radiosurgery had an obliteration rate of $49.0 \%$. Thirteen patients were managed conservatively. Four patients under observation hemorrhaged during a total interval of 429.4 patient-years, translating to an annual risk of $0.9 \%$. Posttreatment hemorrhagic risk by treatment modalities were categorized as follows: surgery \pm embolization $(0.0 \%)$, radiosurgery \pm embolization $(0.8 \%)$, embolization alone $(2.8 \%)$, surgery + radiosurgery \pm embolization $(3.5 \%)$, and observation $(0.8 \%)$. A significantly higher risk of posttreatment hemorrhage was observed for patients with hemorrhagic presentation $(p=0.043)$ in multivariate analysis. Seizure presentation, frontal lobe location, nonheadache presentation, and treatment modality were significantly associated with increased risk of poor functional outcomes.
\end{abstract}

CONCLUSIONS In this study of pediatric patients with AVMs, the natural history of hemorrhage was relatively low at $0.9 \%$. Resection remained the optimal management for hemorrhage control and functional outcome perseverance in these pediatric patients with AVMs. AVM obliteration is a valid treatment goal, especially for patients with ruptured presentation, to prevent further hemorrhages later in life.

http://thejns.org/doi/abs/10.3171/2016.3.PEDS15715

KEY WORDS arteriovenous malformation; hemorrhage; natural history; vascular disorders

$\mathrm{B}$ RAIN arteriovenous malformations (AVMs) are the leading cause of intracranial hemorrhages in pediatric patients, ${ }^{21}$ and account for $30 \%-50 \%$ of all pediatric spontaneous cerebral hemorrhages. ${ }^{4,8,12,52}$ Existing studies show the overall mortality rate of pediatric patients after initial hemorrhage is $25 \% .{ }^{25}$ Approximately $20.2 \%-40.6 \%^{3,8,16}$ of all patients who hemorrhage develop residual neurological deficits. Despite an established annual hemorrhagic risk of $1.9 \%-4.61 \%$ in the general population, $, 1,7,10,45,53$ the risk of hemorrhage in pediatric patients is not entirely understood. Nevertheless, the high cumulative hemorrhagic risk, given the long life expectancy in pediatric patients, warrants definitive treatment of the AVM to prevent hemorrhages later in life. Current treatment options include microsurgery, radiosurgery, embolization, or a combination of therapies. ${ }^{8}$ The treatment

ABBREVIATIONS $\mathrm{AVM}=$ arteriovenous malformation; $\mathrm{Cl}=$ confidence interval; $\mathrm{HR}=$ hazard ratio; $\mathrm{mRS}=$ modified Rankin Scale; $\mathrm{RE}=$ radiosurgery \pm embolization; $\mathrm{SE}=$ surgery \pm embolization; SM = Spetzler-Martin; SR = surgery + radiosurgery \pm embolization.

SUBMITTED December 10, 2015. ACCEPTED March 2, 2016.

INCLUDE WHEN CITING Published online May 6, 2016; DOI: 10.3171/2016.3.PEDS15715. 
decision-making process involves a balanced tradeoff among subsequent hemorrhagic risk, patient functional status, and treatment risk with each modality. To the best of our knowledge, most large population studies regarding pediatric AVMs have predominantly focused on radiosurgery. Direct comparisons to elucidate posttreatment hemorrhagic risk and functional outcomes across different modalities have not been fully explored in a long-term follow-up study. ${ }^{21,40,52}$

In this study we present our institutional experience over 23 years to further elucidate the natural history and posttreatment hemorrhagic risk of AVMs in pediatric patients and to clarify the effect of each treatment modality on hemorrhagic control. Conservatively managed patients were also included in the study to better contrast the treatment effect of each modality. To provide a more comprehensive understanding of prognosis in our pediatric AVM cohort, we also included functional outcomes in our analysis.

\section{Methods \\ Study Population}

We performed a retrospective chart review of all patients with a confirmed diagnosis of intracranial AVM evaluated at The Johns Hopkins Medical Institutions from January 1990 through December 2013. Patients with multiple AVMs and hereditary hemorrhagic telangiectasia were excluded. Pediatric cases were isolated from the database of all AVMs with a cutoff age of 18 years at diagnosis. Cases were also excluded if patients had unobtainable critical information, or if the patient was lost to follow-up.

\section{Definition of Variables}

The primary outcome was defined as incidence rate of hemorrhage in untreated AVMs, as well as posttreatment annualized hemorrhagic risk. To fully appreciate the treatment effect on functional outcome, we included modified Rankin Scale (mRS) scores of the patient at the last follow-up evaluation as our secondary outcome. The mRS score was applied from a retrospective review of documentation of patient functional outcomes and neurological examinations, and we further dichotomized the outcomes into good (mRS score $\leq 1$ ) and poor (mRS score $>1$ ). Other modifiers obtained from the records included: age at diagnosis, sex, presenting symptoms, mRS score at baseline, AVM angioarchitectural characteristics, treatmentrelated variables, obliteration rate, hemorrhage incidence, and functional outcome represented by $\mathrm{mRS}$ scores upon follow-up visits. Our study divided treatment modalities into 5 distinct groups, which included: surgery \pm embolization (SE, microsurgery with/without embolization), radiosurgery \pm embolization ( $\mathrm{RE}$, radiosurgery with/without embolization), surgery + radiosurgery \pm embolization (SR, surgery and radiosurgery with/without embolization), embolization alone, and observation or conservative management. Radiosurgery and embolization were introduced to our institution before 1990 and were therefore an available treatment option for the entire investigation period. Of note, the only 2 patients who were in SR underwent salvage radiosurgery after incomplete resection. These 2 patients presented with hematoma requiring immediate evacuation, and the AVM was subsequently found. An exploratory attempt at obliterating the lesion was initiated, and the AVM could only be partially resected. We considered these cases to be distinctly different from planned surgical procedures with preoperative angiograms, and therefore listed these patients as a separate group (SR).

We defined the natural history risk of AVMs as the annual risk of hemorrhage within the observation period, which was generated by calculating the total number of patients who hemorrhaged divided by total patient-years within the investigated time interval. For patients who underwent conservative management, this period was the interval from diagnosis to last follow-up. For patients who were treated, the observation period was from diagnosis to time of treatment. To measure the effect of treatment on hemorrhagic control, we also included posttreatment (follow-up) hemorrhagic risk in our analysis. Our posttreatment interval included the time from the first treatment to the last follow-up evaluation.

\section{Statistical Analysis}

We used the Student t-test or Wilcoxon rank-sum test for continuous variables, and Fisher's exact test or chisquare test for categorical variables. For survival analysis, events were defined as first hemorrhage after treatment. The Kaplan-Meier curve was created with censored data, and the log-rank test was used for detection of differences between two different curves. Cox proportional hazard regression analysis was used to associate factors with hemorrhagic risk. Factors that were statistically significant or deemed clinically significant in univariate analysis were included into a multivariate model. A p value $<0.05$ was defined as statistically significant, and all $\mathrm{p}$ values were reported as 2-sided. All statistical analyses were performed using R statistical software (version 3.1.1).

\section{Results}

\section{Patient Baseline Characteristics}

A total of 124 pediatric AVM cases were retrieved from 683 AVM cases in our database. After excluding those lost to follow-up, 90 patients $(72.6 \%)$ remained. The average age of all patients at diagnosis was $13.3 \pm 3.8$ years, and the median age was 14 years (range $3-18$ years), with $43.3 \%$ of the cohort being male (Table 1). Eighty-nine (98.9\%) of the 90 patients in our cohort were symptomatic, and the two most common symptoms were headache $(61.1 \%)$ and seizure (43.3\%). Of all patients, $41.1 \%(\mathrm{n}=$ 37) presented with rupture, and 40 patients had pretreatment mRS scores $\leq 1$. Spetzler-Martin (SM) grades of all AVMs were as follows: Grade 1 (7.8\%), Grade $2(30 \%)$, Grade $3(33.3 \%)$, Grade 4 (20\%), and Grade 5 (8.9\%). The average AVM size was $3.4 \pm 1.9 \mathrm{~cm}$.

Fifty patients received radiosurgery, 18 patients underwent resection, 13 patients were followed conservatively, 7 patients underwent embolization only, and 2 patients were treated with incomplete resection with salvage radiosurgery. The average follow-up length was $9.95 \pm 12.54$ years, and the overall AVM obliteration rate in treated patients was $59.7 \%$. The obliteration rate for each modality was as 
follows: SE (100\%), RE (49.0\%), SR (100\%), embolization (16.7\%), observation $(0.0 \%)$. Other baseline characteristics are also listed in Table 1.

\section{Hemorrhagic Risk of AVMs}

Factors associated with hemorrhagic presentation are summarized in Table 2. Smaller AVM size was the only variable to be significantly associated with ruptured presentation ( $p<0.001)$. As described above, we examined hemorrhagic risk in our cohort in two distinct stages: the observation period and the posttreatment (follow-up) period. For the natural course of AVMs, 4 patients hemorrhaged during a total observation interval period of 429.4 patient-years, yielding an annualized hemorrhagic rate of $0.9 \%$ per patient. Regarding the posttreatment hemorrhagic rate, 10 patients hemorrhaged over 895.4 patientsyears, corresponding to an annualized rate of $1.1 \%$ per patient. The annualized hemorrhagic rate for each treatment modality was as follows: SE $(0.0 \%, \mathrm{n}=18), \mathrm{RE}(0.8 \%$, $\mathrm{n}=51), \mathrm{SR}(3.5 \%, \mathrm{n}=2)$, and embolization $(2.8 \%, \mathrm{n}=$ 6; Table 3). No patients hemorrhaged after microsurgical resection, and 4 patients $(7.8 \%)$ hemorrhaged after radiosurgery, with an average treatment to hemorrhage interval of 13.6 years. The earliest follow-up hemorrhage occurred at 4.5 years. These results were comparable or better than patients under conservative management. In contrast, onethird of the patients who were treated solely with embolization hemorrhaged during follow-up. Both patients with follow-up hemorrhage were initially recommended for embolization followed by radiosurgery, and both were lost to follow-up after the first embolization with partial obliteration, and eventually returned with a hemorrhage. All patients with hemorrhage in this group presented with a ruptured AVM. Of note, both patients in the SR group experienced recurrence of hemorrhage during the follow-up period and eventually underwent salvage radiosurgery to reach complete obliteration, translating to an annualized hemorrhagic rate of $3.5 \%$. Detailed descriptions of followup hemorrhagic rates are shown in Table 3.

To understand the effect of ruptured presentation on subsequent hemorrhages, we compared the posttreatment hemorrhagic risk between patients with and without ruptured presentation (Table 3). The overall hemorrhagic risk rate in patients with ruptured AVMs was higher at $1.9 \%$ per patient per year compared with patients with unruptured AVMs ( $0.6 \%$ per patient per year). When investigating specific treatment modalities, we noticed that this difference was most prominent in the embolization $(4.6 \%$ vs $0 \%$ ) and observation groups (1.6\% vs $0 \%)$. The annualized hemorrhagic risk did not significantly differ between ruptured and unruptured presentation in the microsurgery or radiosurgery groups. Kaplan-Meier analysis revealed that ruptured presentation had a significantly higher risk of developing a first follow-up hemorrhage than unruptured presentation (Fig. 1). A log-rank test of the Kaplan-Meier curve revealed a significant association $(p=0.023)$. Univariate Cox regression analysis suggested that ruptured presentation was the only study factor associated with risk of subsequent hemorrhage (Table 4). However, to adjust for possible confounders, treatment modality was forced into the final model. According to the final multivariate
TABLE 1. Baseline characteristics of all patients

\begin{tabular}{|c|c|}
\hline Parameters & All Patients $(n=90)$ \\
\hline \multicolumn{2}{|l|}{ Demographics } \\
\hline Mean age at diagnosis in yrs (SD) & $13.2(3.8)$ \\
\hline \multicolumn{2}{|l|}{$\operatorname{Sex}(\%)$} \\
\hline Males & $39(43.3)$ \\
\hline Females & $51(56.7)$ \\
\hline \multicolumn{2}{|l|}{ Race (\%) } \\
\hline White & $57(63.3)$ \\
\hline Black & $20(22.2)$ \\
\hline Asian & $3(3.3)$ \\
\hline Hispanic & $4(4.4)$ \\
\hline Others & $6(6.6)$ \\
\hline \multicolumn{2}{|l|}{ Presentation (\%) } \\
\hline Ruptured presentation & $37(41.1)$ \\
\hline Pretreatment mRS score $\leq 1$ & $40(44.4)$ \\
\hline Presenting symptoms & $89(98.9)$ \\
\hline Seizure & $39(43.3)$ \\
\hline Headache & $55(61.1)$ \\
\hline Visual disturbance & $13(14.4)$ \\
\hline Speech disturbance & $13(14.4)$ \\
\hline Weakness & $18(20)$ \\
\hline Imbalance & $6(6.7)$ \\
\hline \multicolumn{2}{|l|}{ Angiographic Ffeatures } \\
\hline Mean AVM size in cm (SD) & $3.4(1.9)$ \\
\hline Eloquence (\%) & $66(73.3)$ \\
\hline Deep venous drainage (\%) & $46(51.1)$ \\
\hline \multicolumn{2}{|l|}{ SM Grade (\%) } \\
\hline 1 & $7(7.8)$ \\
\hline 2 & $27(30)$ \\
\hline 3 & $30(33.3)$ \\
\hline 4 & $18(20)$ \\
\hline 5 & $8(8.9)$ \\
\hline \multicolumn{2}{|l|}{ Location (\%) } \\
\hline Frontal & $31(34.4)$ \\
\hline Temporal & $27(30)$ \\
\hline Parietal & $28(31.1)$ \\
\hline Occipital & $16(17.8)$ \\
\hline Brainstem & $4(4.4)$ \\
\hline Cerebellum & $3(3.3)$ \\
\hline Basal ganglia/thalamus & $17(18.9)$ \\
\hline \multicolumn{2}{|l|}{ Treatment } \\
\hline \multicolumn{2}{|l|}{ Treatment modality (\%) } \\
\hline SE & $18(20.0)$ \\
\hline $\mathrm{RE}$ & $51(56.7)$ \\
\hline Embolization only & $6(6.7)$ \\
\hline SR & $2(2.2)$ \\
\hline Observation & $13(14.4)$ \\
\hline \multicolumn{2}{|l|}{ Follow-up } \\
\hline Mean length in yrs (SD) & $9.95(12.54)$ \\
\hline Patients w/ follow-up hemorrhages (\%) & $10(11.1)$ \\
\hline
\end{tabular}


TABLE 2. Factors associated with hemorrhagic presentation

\begin{tabular}{|c|c|c|c|c|}
\hline \multirow[b]{2}{*}{ Parameters } & \multirow[b]{2}{*}{$\begin{array}{c}\text { Total } \\
(n=90)\end{array}$} & \multicolumn{2}{|c|}{ AVM Presentation } & \multirow[b]{2}{*}{$\begin{array}{c}p \\
\text { Value }\end{array}$} \\
\hline & & $\begin{array}{c}\text { Ruptured } \\
(\mathrm{n}=37)\end{array}$ & $\begin{array}{l}\text { Nonruptured } \\
\quad(n=53)\end{array}$ & \\
\hline Mean age in yrs (SD) & $13.3(3.8)$ & $13.0(4.3)$ & $13.4(3.5)$ & 0.617 \\
\hline $\operatorname{Sex}(\%)$ & & & & 0.676 \\
\hline Females & $51(56.7)$ & $20(54.1)$ & $31(58.5)$ & \\
\hline Males & $39(43.3)$ & $17(45.9)$ & $22(41.5)$ & \\
\hline White race (\%) & $57(63.3)$ & $20(54.1)$ & $37(69.8)$ & 0.127 \\
\hline $\begin{array}{l}\text { Mean AVM size in } \mathrm{cm} \\
\text { (SD) }\end{array}$ & $3.4(1.9)$ & $2.8(1.5)$ & $3.8(2.0)$ & $0.009^{*}$ \\
\hline Eloquence (\%) & $66(73.3)$ & $28(75.7)$ & $38(71.7)$ & 0.675 \\
\hline Deep drainage (\%) & $46(51.1)$ & $22(59.5)$ & $24(45.3)$ & 0.186 \\
\hline SM grades (\%) & & & & 0.395 \\
\hline 1 & $7(7.8)$ & $2(5.4)$ & $5(9.4)$ & \\
\hline 2 & $27(30.0)$ & $14(37.8)$ & $13(24.5)$ & \\
\hline 3 & $30(33.3)$ & $14(37.8)$ & $16(30.2)$ & \\
\hline 4 & $18(20.0)$ & $5(13.5)$ & $13(24.5)$ & \\
\hline 5 & $8(8.9)$ & $2(5.4)$ & $6(11.3)$ & \\
\hline Feeder aneurysm (\%) & $10(11.1)$ & $3(8.1)$ & $7(13.2)$ & 0.516 \\
\hline $\begin{array}{l}\text { Intranidal aneurysm } \\
(\%)\end{array}$ & $2(2.2)$ & $0(0.0)$ & $2(3.8)$ & 0.510 \\
\hline $\begin{array}{l}\text { Posterior fossa loca- } \\
\text { tion (\%) }\end{array}$ & $7(7.8)$ & $5(13.5)$ & $2(3.8)$ & 0.119 \\
\hline
\end{tabular}

* Statistically significant $(p<0.05)$.

Cox regression model, the hazard ratio (HR) of developing follow-up hemorrhage was approximately 5 times greater in patients with ruptured presentations compared with unruptured presentations (HR 5.21, 95\% confidence interval [CI] 1.05-25.81, $\mathrm{p}=0.043$ ) after adjusting for treatment modality. Although we did not observe statistical significance across different treatment modalities, as implied by the wide confidence interval, the nonsignificance was likely a result of small sample size. When looking at the HR alone, patients who underwent only embolization had a 6-fold increase in the HR of having a follow-up hemorrhage compared with conservatively managed patients (HR 6.31, 95\% CI 0.42-93.74, $\mathrm{p}=0.181$ ). The univariate and multivariate Cox regression analyses are depicted in detail in Table 4.

\section{Patient Functional Outcomes}

Prior to any treatment, $60 \%$ of all patients had a poor outcome (mRS score $>1$ ), whereas after treatment, the proportion dropped to $32 \%$. Patient functional outcomes improved with most modalities of treatment, including SE (preoperative poor mRS score $67 \%$, postoperative poor mRS score 6\%), RE (preoperative 54\%, postoperative $26 \%$ ), and embolization (preoperative $61.4 \%$, postoperative $28.6 \%$ ). No improvement was observed, however, in the observation group (preoperative $30.8 \%$, postoperative $30.8 \%$ ) or the SR group (preoperative 100\%, postoperative $100 \%)$. The association of treatment modality with followup mRS score was found to be significant $(p=0.039)$. Only 1 patient in the SE group experienced adverse outcome, with $94.1 \%$ of patients achieving an optimal outcome at last follow-up. The proportions of good outcomes in other modalities were as follows: RE (74.0\%), SR (0.0\%), embolization (71.4\%) and observation (69.2\%).

As shown in Table 5, patients presenting with seizures had a significantly higher risk of poor functional outcome $(63.6 \%, p=0.027)$. This was primarily due to uncontrolled seizures at follow-up. Patients with mild presenting symptoms, such as headaches, were more likely to obtain a favorable outcome following appropriate management $(\mathrm{p}=$ 0.025 ). We did not establish a significant association between ruptured presentation and follow-up outcome ( $\mathrm{p}=$ $0.141)$. None of the angiographic features aside from frontal lobe location $(\mathrm{p}<0.001)$ were significantly associated with poor functional outcomes. This is consistent with our clinical experience that most patients with a frontal lobe injury resulted in a constellation of symptoms including personality, mental, cognitive, and even speech disorders. In addition, frontal lobe injury was associated with a higher likelihood of having seizures at follow-up. All of

TABLE 3. Overall patient hemorrhage risk, and risk according to ruptured presentation, at follow-up

\begin{tabular}{lcccccc}
\hline \multicolumn{1}{c}{ Parameters } & Total & SE & RE & Embolization & SR & Observation \\
\hline Overall risk & & & & & & \\
\hline No. of patients & 90 & 18 & 51 & 6 & 2 & 13 \\
\hline Patient-yrs & 895.4 & 45 & 480.5 & 71.6 & 56.5 & 241.9 \\
\hline Patients hemorrhaged (\%) & $10(11.1)$ & $0(0.0)$ & $4(7.8)$ & $2(33.3)$ & $2(100.0)$ & $2(15.4)$ \\
\hline Annual percentage rate & 1.1 & 0 & 0.8 & 2.8 & 3.5 & 0.8 \\
\hline Ruptured presentation & & & & & & 128 \\
\hline Patient-yrs & 367.1 & 18.8 & 120.5 & 43.3 & 56.5 & $2(15.4)$ \\
\hline Patients hemorrhaged (\%) & $7(7.8)$ & $0(0.0)$ & $1(2.0)$ & $2(33.3)$ & $2(100.0)$ & 1.6 \\
\hline Annual percentage rate & 1.9 & 0 & 0.8 & 4.6 & 3.5 & 113.9 \\
\hline Unruptured presentation & & & & & NA & $0(0.0)$ \\
\hline Patient-yrs & 528.3 & 26.2 & 360 & 28.3 & NA & 0 \\
\hline Patients hemorrhaged (\%) & $3(3.3)$ & $0(0.0)$ & $3(5.9)$ & $0(0.0)$ & 0 & NA \\
\hline Annual percentage rate & 0.6 & 0 & 0.8 & & & 0 \\
\hline
\end{tabular}

$\mathrm{NA}=$ not applicable. 


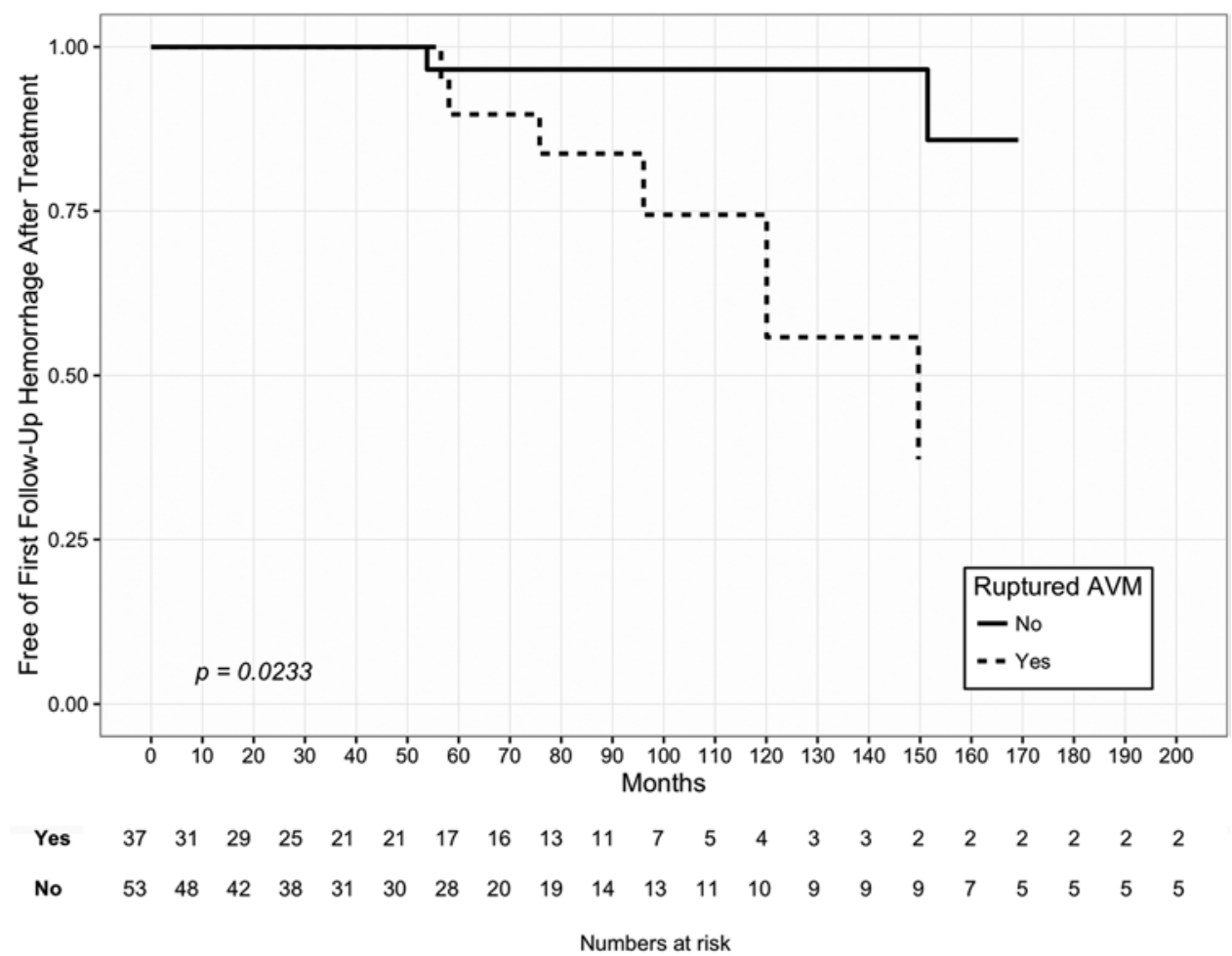

FIG. 1. Kaplan-Meier survival curve of pediatric patients with AVMs free of follow-up hemorrhage according to ruptured presentation. As shown, patients with ruptured presentation had a significantly higher probability of experiencing a sooner onset of followup hemorrhage.

these factors contributed to the limitation of the patients' ability to return to normal school or work, rendering a significantly worse mRS score at last follow-up. Larger AVM size demonstrated a trend toward significance $(\mathrm{p}=0.081)$ in predicting poor functional outcomes.

\section{Discussion}

\section{Hemorrhagic Risk of AVMs}

In this study we present a cohort of 90 pediatric patients with a confirmed diagnosis of intracranial AVM and compared the natural history, posttreatment hemorrhagic risk, and functional prognosis across different treatment modalities. Previous studies have established the risk of hemorrhagic presentation to be $30 \%-82 \%,{ }^{11,14,27,28,53}$ and the natural history of hemorrhage in AVMs is $1.9 \%-4.61 \%$ in the general population. ${ }^{6,7,10,11,15,18}$ In contrast, the natural history of AVMs in pediatric patients is underreported in the existing literature. ${ }^{8,37}$ Darsaut et al. reported a $4.0 \%$ annual risk of hemorrhage in a cohort of 120 treated pediatric patients with AVMs. ${ }^{8}$ Similar to our study, the risk was generated using the time interval from presentation to initial treatment. However, the magnitude of selection bias introduced in the study should not be ignored, because all the patients in their study were selected for treatment and therefore represented a high-risk cohort. The current study reports a natural history of $0.9 \%$ per patient per year, with a total of 429.4 patient-years and a presumably lower-risk cohort with the inclusion of 13 conservatively managed patients (14.4\%). The hypothesis that pediatric AVMs
TABLE 4. Multivariate Cox proportional hazard regression analysis of follow-up hemorrhagic risk

\begin{tabular}{|c|c|c|}
\hline Parameters & $\mathrm{HR}(95 \% \mathrm{Cl})$ & $p$ Value \\
\hline \multicolumn{3}{|l|}{ Univariate analysis } \\
\hline Race (nonwhite vs white) & $1.32(0.26-6.78)$ & 0.743 \\
\hline Mean AVM size (cm) & $0.75(0.50-1.11)$ & 0.144 \\
\hline Ruptured presentation (yes vs no) & $4.38(1.10-17.45)$ & $0.036^{*}$ \\
\hline \multicolumn{3}{|l|}{ Treatment modality } \\
\hline Observation & - & Ref \\
\hline SE & $\mathrm{NA} \dagger$ & $>0.999$ \\
\hline RE & $1.60(0.29-8.83)$ & 0.592 \\
\hline SR & $5.83(0.71-47.70)$ & 0.101 \\
\hline Embolization & $3.26(0.317-39.68)$ & 0.355 \\
\hline Posterior fossa (yes vs no) & NA† & $>0.999$ \\
\hline \multicolumn{3}{|l|}{ Multivariate analysis } \\
\hline Ruptured presentation (yes vs no) & $5.21(1.05-25.81)$ & $0.043^{*}$ \\
\hline \multicolumn{3}{|l|}{ Treatment modality } \\
\hline Observation & - & Ref \\
\hline SE & NA† & $>0.999$ \\
\hline RE & $2.65(0.39-17.89)$ & 0.316 \\
\hline SR & $3.16(0.35-28.28)$ & 0.304 \\
\hline Embolization & $6.31(0.42-93.74)$ & 0.181 \\
\hline
\end{tabular}

Ref $=$ reference.

* Statistically significant $(p<0.05)$.

$\dagger$ Infinite HR reported. 
TABLE 5. Factors associated with good and poor functional outcomes at last follow-up in pediatric patients with AVMs

\begin{tabular}{|c|c|c|c|c|}
\hline Parameters & Total $(n=90)$ & $\begin{array}{l}\text { Good Outcome } \\
\text { (mRS score } \leq 1)\end{array}$ & $\begin{array}{l}\text { Poor Outcome } \\
(\mathrm{mRS} \text { score }>1)\end{array}$ & $p$ Value \\
\hline No. of patients & 90 & 68 & 22 & \\
\hline Mean age in yrs (SD) & $12.71(3.81)$ & $12.99(3.78)$ & $11.86(3.84)$ & 0.290 \\
\hline Sex $(\%)$ & & & & 0.817 \\
\hline Females & $51(56.7)$ & $39(57.4)$ & $12(54.5)$ & \\
\hline Males & $39(43.3)$ & $29(42.6)$ & $10(45.5)$ & \\
\hline Race (\%) & & & & 0.338 \\
\hline White & $57(63.3)$ & $42(61.8)$ & $15(68.2)$ & \\
\hline Black & $20(22.2)$ & $13(19.1)$ & $7(31.8)$ & \\
\hline Asian & $3(3.3)$ & $3(4.4)$ & $0(0.0)$ & \\
\hline Hispanic & $4(4.4)$ & $4(5.9)$ & $0(0.0)$ & \\
\hline Others & $6(6.7)$ & $6(8.8)$ & $0(0.0)$ & \\
\hline Rupture presentation (\%) & $37(41.1)$ & $25(36.8)$ & $12(54.5)$ & 0.141 \\
\hline Pretreatment mRS score $\leq 1(\%)$ & $40(44.4)$ & $33(48.5)$ & $7(31.8)$ & 0.170 \\
\hline \multicolumn{5}{|l|}{ Presenting symptoms (\%) } \\
\hline Seizure & $39(43.3)$ & $25(36.8)$ & $14(63.6)$ & $0.027^{*}$ \\
\hline Headache & $55(61.1)$ & $46(67.6)$ & $9(40.9)$ & $0.025^{*}$ \\
\hline Visual disturbance & $12(13.3)$ & $7(10.3)$ & $5(22.7)$ & 0.136 \\
\hline Speech disturbance & $13(14.4)$ & $10(14.7)$ & $3(13.6)$ & $>0.999$ \\
\hline Weakness & $18(20.0)$ & $12(17.6)$ & $6(27.3)$ & 0.327 \\
\hline Imbalance & $6(6.7)$ & $4(5.9)$ & $2(9.1)$ & 0.632 \\
\hline Mean AVM size in cm (SD) & $3.40(1.92)$ & $3.22(1.84)$ & $3.95(2.09)$ & $0.081 \dagger$ \\
\hline Eloquence (\%) & $66(73.3)$ & $48(70.6)$ & $18(81.8)$ & 0.409 \\
\hline Deep venous drainage (\%) & $46(51.1)$ & $32(47.1)$ & $14(63.6)$ & 0.176 \\
\hline SM grade $(\%)$ & & & & 0.207 \\
\hline 1 & $7(7.8)$ & $7(10.3)$ & $0(0.0)$ & \\
\hline 2 & $27(30.0)$ & $22(32.4)$ & $5(22.7)$ & \\
\hline 3 & $30(33.3)$ & $21(30.9)$ & $9(40.9)$ & \\
\hline 4 & $18(20.0)$ & $14(20.6)$ & $4(18.2)$ & \\
\hline 5 & $8(8.9)$ & $4(5.9)$ & $4(18.2)$ & \\
\hline \multicolumn{5}{|l|}{ Locations (\%) } \\
\hline Frontal & $31(34.4)$ & $17(25.0)$ & $14(63.6)$ & $0.001^{*}$ \\
\hline Temporal & $27(30.0)$ & $22(32.4)$ & $5(22.7)$ & 0.392 \\
\hline Parietal & $28(31.1)$ & $21(30.9)$ & $7(31.8)$ & 0.934 \\
\hline Occipital & $16(17.8)$ & $14(20.6)$ & $2(9.1)$ & 0.339 \\
\hline Brainstem & $4(4.4)$ & $3(4.4)$ & $1(4.5)$ & $>0.999$ \\
\hline Basal ganglia/thalamus & $9(10.0)$ & $7(10.3)$ & $2(9.1)$ & $>0.999$ \\
\hline Treatment modality (\%) & & & & $0.039^{*}$ \\
\hline SE & $18(20.0)$ & $17(25.0)$ & $1(4.5)$ & \\
\hline $\mathrm{RE}$ & $50(55.6)$ & $37(54.4)$ & $13(59.1)$ & \\
\hline SR & $2(2.2)$ & $0(0.0)$ & $2(9.1)$ & \\
\hline Embolization & $7(7.8)$ & $5(7.4)$ & $2(9.1)$ & \\
\hline Observation & $13(14.4)$ & $9(13.2)$ & $4(18.2)$ & \\
\hline
\end{tabular}

are more likely to rupture compared with adult AVMs remains controversial, ${ }^{8}$ and the natural history of these lesions needs to be further clarified in a larger cohort or meta-analysis of the existing literature. However, given the long life expectancy of pediatric patients and high mor- tality and morbidity associated with AVM-related hemorrhage, $1,10,25,27,43,44$ pediatric patients with AVMs should continue to seek timely definitive treatment for obliteration of the lesion to reduce the risk of hemorrhage.

Despite advancement of techniques in AVM manage- 
ment, the risk of hemorrhage persists after treatment and is reported to be $1.4 \%$ overall per patient per year in the general patient population. ${ }^{48}$ In regard to pediatric patients with AVMs, this rate is $0.3 \%-4.3 \%$ for patients who underwent radiosurgery, $2,3,8,9,17,21,29,37,42,43,54,56,57$ and $0 \%-0.3 \%$ for patients after resection..$^{8,16,50}$ To the best of our knowledge, this is the first study attempting to compare posttreatment hemorrhagic risk across different treatment modalities in a single cohort of pediatric patients with AVMs. According to our results, patients treated with microsurgical resection experienced the best outcome with no subsequent hemorrhages $(0.0 \%)$. The risk of posttreatment hemorrhage $(0.8 \%)$ in patients treated with radiosurgery was at the lower end of the reported rate in the literature, and it is equivalent to the risk of patients undergoing conservative management $(0.8 \%)$. Conversely, the risk of subsequent hemorrhage has a 3- to 4-fold increase compared with radiosurgery when patients are treated with embolization as the single treatment modality $(2.8 \%)$ or incomplete resection (3.5\%, SR group). The disparity in hemorrhage control for different management modalities underscores the importance of identifying and adjusting for each distinct treatment modality within a study. Failing to do so will likely result in misinterpretation of the treatment effect, which was one of the significant criticized flaws in the trial named A Randomized Trial of Unruptured Brain Arteriovenous Malformations (ARUBA), where all treatment modalities were classified as 1 single arm.,33,34,41 Our overall obliteration rate was comparatively lower than some reported series. This is largely due to the fact that most of the patients in our cohort were treated via radiosurgery, and the actuarial obliteration rate of radiosurgery in pediatric patients is largely variable in the reported literature (18\%-88.1\%, with most around 30\%-50\%)..$^{2,9,40,42,49,57}$ Our AVM obliteration rate in pediatric patients falls within this range, albeit lower than reported in adult series.

\section{Factors Associated With Risk of Hemorrhage}

Numerous factors have been proposed to significantly increase the risk of hemorrhage in the adult population with AVMs. These factors include ruptured presentation, small size, residual AVM, deep venous drainage, posterior fossa location, and associated aneurysms. ${ }^{20,22,26,28,30,32,38,39,45,46,51}$ Noticeably, recent studies also demonstrated a higher trend of hemorrhagic risk in nonwhite populations. ${ }^{24,54}$ Our study confirmed the association of small AVM size with ruptured presentation, but failed to observe a significant difference in other variables. This is likely due to limited statistical utility given the relatively small size of the cohort. The identification of these factors is crucial for accurately stratifying patients for appropriate management. However, despite a well-known list of risk factors in the adult population, fewer studies have focused on the pediatric population. The direct application of adult risk factors to the pediatric population may not be warranted, as some angioarchitectural features between the two populations are distinctly different, as suggested by Hetts et al. ${ }^{19}$ Therefore, a separate investigation in a pediatric population is worthwhile to improve the accuracy of risk evaluation. According to the data presented in this study, ruptured AVM presentation has a significant impact on posttreat- ment hemorrhagic risk, even after adjusting for treatment modality; the HR of acquiring a subsequent hemorrhage in patients with a presenting hemorrhage was 5 times greater compared with unruptured counterparts. This result highlights the importance of directing pediatric patients with ruptured presentations to definitive modalities, such as SE or RE if possible, where the posttreatment hemorrhagic risk was shown to be comparatively low $(0.0 \%-0.8 \%)$.

\section{Functional Outcomes in Pediatric Patients With AVMs}

Functional outcomes in pediatric patients with AVMs is a major element in the treatment decision-making process. Nair et al. demonstrated that $86.1 \%$ of pediatric patients with low-grade AVMs achieve a good functional outcome after microsurgical resection. ${ }^{35}$ In comparison, in a radiosurgical cohort of 116 pediatric patients with AVMs reported recently by Hanakita et al., only 10 patients were reported to develop adverse events, rendering a $91.4 \%$ optimal functional outcome, with prior AVM hemorrhage showing marginal association with worse functional outcomes. ${ }^{17}$ In a more comprehensive analysis presented by Darsaut et al., where all major modalities were included, the overall proportion of patients achieving good functional outcomes was $74.2 \%$, in which high grade, left side, and poor baseline mRS score were significant predictors in the multivariate analysis. ${ }^{8}$ These data are largely consistent with those in our study. Of note, our data demonstrated that seizure presentation was significantly associated with poor outcome, which was most likely a result of intractable seizures at follow-up. The limitation placed by seizures and antiepileptic medications on patients' daily activities has a significant impact on patients' quality of life, because most patients were unlikely to return to driving or activities requiring continuous concentration. Similarly, frontal lobe location is also associated with increased follow-up epilepsy. Furthermore, patients with frontal lobe injury are also more likely to experience mental, emotional or cognitive/memory changes, inhibiting return to normal social functionality. ${ }^{47}$ From our experience, although difficult to quantify, these changes significantly affect the quality of life in these patients, particularly affecting academic performance, and should therefore be more emphasized in future pediatric AVM studies. Finally, although patients with planned resection appeared to sustain a better functional outcome than other groups, comparisons of functional outcomes between different treatment modalities is hardly conclusive under the influence of selection bias. Future studies with larger patient populations are warranted to fully adjust pretreatment selection biases to elucidate the impact of specific treatment modalities on patient functional outcomes.

\section{Study Limitations}

Our study has several limitations that need to be clarified to avoid misinterpretation of our data. Similar to other pediatric AVM studies, our study represents a retrospective observational cohort with a limited number of cases and considerable data attrition. The relatively small sample size places significant limitations on statistical sensitivity, varies distributions across investigated groups, and explains the wide CIs in multivariate Cox regression 
analysis. However, to our knowledge, this study cohort remains one of the largest studies in the existing literature concerning a pediatric population with AVMs. We retained $72.6 \%$ of all pediatric patients with AVMs found in our institutional database without intentional exclusion of cases, reducing the likelihood of introducing a significant sampling bias. Our study included patients over a 23year span, with patients undergoing treatment with radiation and embolization starting before 1990; therefore, the advancements in treatment devices or techniques might not be adequately reflected. During this time, a transition from single modality to multimodality treatment, and increased emphasis on perseverance of patient functional outcomes, has been observed. While contemporary series might demonstrate a better outcome, inclusion of earlier patients with longer follow-up periods is also indicated to fully appreciate the occurrence of rare events such as posttreatment hemorrhages. Another limitation of this study is the relatively rare occurrence of follow-up hemorrhages, resulting in a dramatic increase in incidence rate when a single event occurs. Some studies assumed AVMs are congenital and defined the risk exposure period from birth to presentation. However, we remain skeptical to use this calculation method, given that an increasing body of evidence demonstrated the acquired nature of this disease..$^{13,23,31,36,55}$ Finally, the majority of our treated patients underwent radiosurgery, which was seemingly counterintuitive given that $71.1 \%$ of our patients were SM Grade I-III with surgically favorable profiles. However, small to moderately sized AVMs were also treatable by radiosurgery, and this modality was frequently favored by patients and parents in pursuit of reduced procedure invasiveness. This result is also consistent with the majority of the body of literature reporting radiosurgical series of pediatric AVMs.

\section{Conclusions}

Although the annual risk of hemorrhage in the natural history of pediatric AVMs is relatively low at $0.9 \%$, AVM patients sustain a lifelong risk of hemorrhage. Therefore, AVMs should be definitively obliterated to prevent future hemorrhage, especially in the pediatric population, where higher accumulative risk is expected. Patients with ruptured presentation have a significantly increased risk of repeat hemorrhages and should therefore be directed to timely definitive treatment whenever safely possible. Seizure presentation, frontal lobe, and nonheadache presentations were associated with increased risk of poor functional outcomes in this study. Our study results suggested that for patients with favorable risk profiles, resection might be the optimal treatment modality in reducing hemorrhagic risk and preserving functional outcomes. Provided with the scarcity of existing literature, more studies regarding the pediatric population with AVMs are warranted to enable pooling of study data for future evidence synthesis.

\section{References}

1. Arteriovenous Malformation Study Group: Arteriovenous malformations of the brain in adults. $\mathbf{N}$ Engl J Med 340:1812-1818, 1999

2. Börcek AÖ, Emmez H, Akkan KM, Öcal Ö, Kurt G, Aykol $\mathrm{S}$, et al: Gamma Knife radiosurgery for arteriovenous mal- formations in pediatric patients. Childs Nerv Syst 30:14851492, 2014

3. Buis DR, Dirven CMF, Lagerwaard FJ, Mandl ES, Lycklama A Nijeholt GJ, Eshghi DS, et al: Radiosurgery of brain arteriovenous malformations in children. J Neurol 255:551-560, 2008

4. Celli P, Ferrante L, Palma L, Cavedon G: Cerebral arteriovenous malformations in children. Clinical features and outcome of treatment in children and in adults. Surg Neurol 22:43-49, 1984

5. Cockroft KM, Jayaraman MV, Amin-Hanjani S, Derdeyn CP, McDougall CG, Wilson JA: A perfect storm: how A Randomized Trial of Unruptured Brain Arteriovenous Malformations' (ARUBA's) trial design challenges notions of external validity. Stroke 43:1979-1981, 2012

6. da Costa L, Thines L, Dehdashti AR, Wallace MC, Willinsky RA, Tymianski M, et al: Management and clinical outcome of posterior fossa arteriovenous malformations: report on a single-centre 15-year experience. J Neurol Neurosurg Psychiatry 80:376-379, 2009

7. da Costa L, Wallace MC, terBrugge KG, O'Kelly C, Willinsky RA, Tymianski M: The natural history and predictive features of hemorrhage from brain arteriovenous malformations. Stroke 40:100-105, 2009

8. Darsaut TE, Guzman R, Marcellus ML, Edwards MS, Tian L, Do HM, et al: Management of pediatric intracranial arteriovenous malformations: experience with multimodality therapy. Neurosurgery 69:540-556, 2011

9. Ding D, Xu Z, Yen CP, Starke RM, Sheehan JP: Radiosurgery for unruptured cerebral arteriovenous malformations in pediatric patients. Acta Neurochir (Wien) 157:281-291, 2015

10. Fleetwood IG, Steinberg GK: Arteriovenous malformations. Lancet 359:863-873, 2002

11. Fults D, Kelly DL Jr: Natural history of arteriovenous malformations of the brain: a clinical study. Neurosurgery 15:658-662, 1984

12. Garza-Mercado R, Cavazos E, Tamez-Montes D: Cerebral arteriovenous malformations in children and adolescents. Surg Neurol 27:131-140, 1987

13. Gonzalez LF, Bristol RE, Porter RW, Spetzler RF: De novo presentation of an arteriovenous malformation. Case report and review of the literature. J Neurosurg 102:726-729, 2005

14. Graf CJ, Perret GE, Torner JC: Bleeding from cerebral arteriovenous malformations as part of their natural history. $\mathbf{J}$ Neurosurg 58:331-337, 1983

15. Gross BA, Du R: Natural history of cerebral arteriovenous malformations: a meta-analysis. J Neurosurg 118:437-443, 2013

16. Gross BA, Storey A, Orbach DB, Scott RM, Smith ER: Microsurgical treatment of arteriovenous malformations in pediatric patients: the Boston Children's Hospital experience. J Neurosurg Pediatr 15:71-77, 2015

17. Hanakita S, Koga T, Shin M, Igaki H, Saito N: The long-term outcomes of radiosurgery for arteriovenous malformations in pediatric and adolescent populations. J Neurosurg Pediatr 16:222-231, 2015

18. Hernesniemi JA, Dashti R, Juvela S, Väärt K, Niemelä M, Laakso A: Natural history of brain arteriovenous malformations: a long-term follow-up study of risk of hemorrhage in 238 patients. Neurosurgery 63:823-831, 2008

19. Hetts SW, Cooke DL, Nelson J, Gupta N, Fullerton H, Amans $\mathrm{MR}$, et al: Influence of patient age on angioarchitecture of brain arteriovenous malformations. AJNR Am J Neuroradiol 35:1376-1380, 2014

20. Kader A, Young WL, Pile-Spellman J, Mast H, Sciacca RR, Mohr JP, et al: The influence of hemodynamic and anatomic factors on hemorrhage from cerebral arteriovenous malformations. Neurosurgery 34:801-808, 1994 
21. Kano H, Kondziolka D, Flickinger JC, Yang HC, Flannery TJ, Awan NR, et al: Stereotactic radiosurgery for arteriovenous malformations, part 2: management of pediatric patients. J Neurosurg Pediatr 9:1-10, 2012

22. Karlsson B, Lax I, Söderman M: Risk for hemorrhage during the 2-year latency period following Gamma Knife radiosurgery for arteriovenous malformations. Int J Radiat Oncol Biol Phys 49:1045-1051, 2001

23. Kilbourn KJ, Spiegel G, Killory BD, Kureshi I: Case report of a de novo brainstem arteriovenous malformation in an 18 -year-old male and review of the literature. Neurosurg Rev 37:685-691, 2014

24. Kim H, Sidney S, McCulloch CE, Poon KYT, Singh V, Johnston SC, et al: Racial/ethnic differences in longitudinal risk of intracranial hemorrhage in brain arteriovenous malformation patients. Stroke 38:2430-2437, 2007

25. Kondziolka D, Humphreys RP, Hoffman HJ, Hendrick EB, Drake JM: Arteriovenous malformations of the brain in children: a forty year experience. Can J Neurol Sci 19:40-45, 1992

26. Laakso A, Dashti R, Juvela S, Isarakul P, Niemelä M, Hernesniemi J: Risk of hemorrhage in patients with untreated Spetzler-Martin grade IV and V arteriovenous malformations: a long-term follow-up study in 63 patients. Neurosurgery 68:372-378, 2011

27. Laakso A, Dashti R, Seppänen J, Juvela S, Väärt K, Niemelä $\mathrm{M}$, et al: Long-term excess mortality in 623 patients with brain arteriovenous malformations. Neurosurgery 63:244255,2008

28. Langer DJ, Lasner TM, Hurst RW, Flamm ES, Zager EL, King JT: Hypertension, small size, and deep venous drainage are associated with risk of hemorrhagic presentation of cerebral arteriovenous malformations. Neurosurgery 42:481-489, 1998

29. Levy EI, Niranjan A, Thompson TP, Scarrow AM, Kondziolka D, Flickinger JC, et al: Radiosurgery for childhood intracranial arteriovenous malformations. Neurosurgery 47:834-842, 2000

30. Lv X, Wu Z, Jiang C, Yang X, Li Y, Sun Y, et al: Angioarchitectural characteristics of brain arteriovenous malformations with and without hemorrhage. World Neurosurg 76:95-99, 2011

31. Miller BA, Bass DI, Chern JJ: De novo AVM formation. Childs Nerv Syst 31:1023, 2015

32. Mine S, Hirai S, Ono J, Yamaura A: Risk factors for poor outcome of untreated arteriovenous malformation. J Clin Neurosci 7:503-506, 2000

33. Mohr JP, Moskowitz AJ, Parides M, Stapf C, Young WL: Hull down on the horizon: A Randomized Trial of Unruptured Brain Arteriovenous Malformations (ARUBA) trial. Stroke 43:1744-1745, 2012

34. Mohr JP, Parides MK, Stapf C, Moquete E, Moy CS, Overbey JR, et al: Medical management with or without interventional therapy for unruptured brain arteriovenous malformations (ARUBA): a multicentre, non-blinded, randomised trial. Lancet 383:614-621, 2014

35. Nair AP, Kumar R, Mehrotra A, Srivastava AK, Sahu RN, Nair P: Clinical, radiological profile and outcome in pediatric Spetzler-Martin grades I-III arteriovenous malformations. Childs Nerv Syst 28:593-598, 2012

36. Neil JA, Li D, Stiefel MF, Hu YC: Symptomatic de novo arteriovenous malformation in an adult: case report and review of the literature. Surg Neurol Int 5:148, 2014

37. Niazi TN, Klimo P Jr, Anderson RCE, Raffel C: Diagnosis and management of arteriovenous malformations in children. Neurosurg Clin N Am 21:443-456, 2010

38. Pollock BE, Flickinger JC, Lunsford LD, Bissonette DJ, Kondziolka D: Factors that predict the bleeding risk of cerebral arteriovenous malformations. Stroke 27:1-6, 1996
39. Pollock BE, Flickinger JC, Lunsford LD, Bissonette DJ, Kondziolka D: Hemorrhage risk after stereotactic radiosurgery of cerebral arteriovenous malformations. Neurosurgery 38:652-661, 1996

40. Potts MB, Sheth SA, Louie J, Smyth MD, Sneed PK, McDermott MW, et al: Stereotactic radiosurgery at a low marginal dose for the treatment of pediatric arteriovenous malformations: obliteration, complications, and functional outcomes. J Neurosurg Pediatr 14:1-11, 2014

41. Russin J, Spetzler R: Commentary: The ARUBA trial. Neurosurgery 75:E96-E97, 2014

42. Sheth SA, Potts MB, Sneed PK, Young WL, Cooke DL, Gupta N, et al: Angiographic features help predict outcome after stereotactic radiosurgery for the treatment of pediatric arteriovenous malformations. Childs Nerv Syst 30:241-247, 2014

43. Smyth MD, Sneed PK, Ciricillo SF, Edwards MS, Wara WM, Larson DA, et al: Stereotactic radiosurgery for pediatric intracranial arteriovenous malformations: the University of California at San Francisco experience. J Neurosurg 97:4855,2002

44. Spetzler RF, Martin NA: A proposed grading system for arteriovenous malformations. J Neurosurg 65:476-483, 1986

45. Stefani MA, Porter PJ, terBrugge KG, Montanera W, Willinsky RA, Wallace MC: Angioarchitectural factors present in brain arteriovenous malformations associated with hemorrhagic presentation. Stroke 33:920-924, 2002

46. Turjman F, Massoud TF, Viñuela F, Sayre JW, Guglielmi G, Duckwiler G: Correlation of the angioarchitectural features of cerebral arteriovenous malformations with clinical presentation of hemorrhage. Neurosurgery 37:856-862, 1995

47. Vachhrajani S, de Ribaupierre S, Otsubo H, Ochi A, Weiss SK, Donner EJ, et al: Neurosurgical management of frontal lobe epilepsy in children. J Neurosurg Pediatr 10:206-216, 2012 (Erratum in J Neurosurg Pediatr 10:565, 2012)

48. van Beijnum J, van der Worp HB, Buis DR, Al-Shahi Salman R, Kappelle LJ, Rinkel GJE, et al: Treatment of brain arteriovenous malformations: a systematic review and meta-analysis. JAMA 306:2011-2019, 2011

49. Walcott BP, Hattangadi-Gluth JA, Stapleton CJ, Ogilvy CS, Chapman PH, Loeffler JS: Proton beam stereotactic radiosurgery for pediatric cerebral arteriovenous malformations. Neurosurgery 74:367-374, 2014

50. Walkden JS, Zador Z, Herwadkar A, Kamaly-Asl ID: Use of intraoperative Doppler ultrasound with neuronavigation to guide arteriovenous malformation resection: a pediatric case series. J Neurosurg Pediatr 15:291-300, 2015

51. Yamada S, Takagi Y, Nozaki K, Kikuta K, Hashimoto N: Risk factors for subsequent hemorrhage in patients with cerebral arteriovenous malformations. J Neurosurg 107:965972, 2007

52. Yang SY, Kim DG, Chung HT, Paek SH: Radiosurgery for unruptured cerebral arteriovenous malformations: long-term seizure outcome. Neurology 78:1292-1298, 2012

53. Yang W, Caplan JM, Ye X, Wang JY, Braileanu M, Rigamonti D, et al: Racial associations with hemorrhagic presentation in cerebral arteriovenous malformations. World Neurosurg 84:461-469, 2015

54. Yen CP, Monteith SJ, Nguyen JH, Rainey J, Schlesinger DJ, Sheehan JP: Gamma Knife surgery for arteriovenous malformations in children. J Neurosurg Pediatr 6:426-434, 2010

55. Yeo JJY, Low SYY, Seow WT, Low DCY: Pediatric de novo cerebral AVM: report of two cases and review of literature. Childs Nerv Syst 31:609-614, 2015

56. Yeon JY, Shin HJ, Kim JS, Hong SC, Lee JI: Clinico-radiological outcomes following Gamma Knife radiosurgery for pediatric arteriovenous malformations. Childs Nerv Syst 27:1109-1119, 2011

57. Zabel-du Bois A, Milker-Zabel S, Huber P, Schlegel W, De- 
bus J: Pediatric cerebral arteriovenous malformations: the role of stereotactic linac-based radiosurgery. Int J Radiat Oncol Biol Phys 65:1206-1211, 2006

\section{Disclosures}

The authors report no conflict of interest concerning the materials or methods used in this study or the findings specified in this paper.

\section{Author Contributions}

Conception and design: Ahn, Yang, Caplan, Hung, Colby, Coon, Tamargo, Huang. Acquisition of data: Yang, Anderson-Keightly,
Hung. Analysis and interpretation of data: Yang, AndersonKeightly. Drafting the article: Yang, Anderson-Keightly. Critically revising the article: Ahn, Yang, Westbroek, Caplan, Rong, Huang. Reviewed submitted version of manuscript: Ahn, Yang, Westbroek, Caplan, Rong, Colby, Coon, Tamargo, Huang. Approved the final version of the manuscript on behalf of all authors: Ahn. Statistical analysis: Yang, Westbroek, Rong. Administrative/technical/material support: Ahn, Yang, Westbroek, Caplan, Hung, Colby, Coon, Tamargo, Huang. Study supervision: Ahn, Yang, Huang.

\section{Correspondence}

Edward S. Ahn, Johns Hopkins Hospital, 600 N Wolfe St., Phipps Ste. 560, Baltimore, MD 21287. email: eahn4@jhmi.edu. 